\title{
Delay of Type I diabetes in high risk, first degree relatives by parenteral antigen administration: the Schwabing Insulin Prophylaxis Pilot Trial
}

\author{
M.Füchtenbusch ${ }^{1}$, W. Rabl ${ }^{2}$, B. Grassl ${ }^{2}$, W.Bachmann ${ }^{3}$, E. Standl ${ }^{1}$, A.-G.Ziegler ${ }^{1}$ \\ 1 3rd Medical Department, Hospital München-Schwabing, and Diabetes Research Institute, Munich, Germany \\ ${ }^{2}$ Children's Hospital, Technical University, Munich, Germany \\ ${ }^{3}$ Community Hospital, Kronach, Germany
}

Summary The Schwabing Insulin Prophylaxis Trial is a randomised, controlled pilot study designed to examine whether insulin therapy can delay or prevent the clinical onset of Type I diabetes in high risk first degree relatives of people with the disease. First degree relatives of patients with Type I diabetes, who were aged 4 years or more, had an islet cell antibody (ICA) value more than 20 Junevile Diabetes Foundation Units (JDF-U), a reduced first phase insulin response (FPI) to an i.v. glucose tolerance test less than the 5th centile, and a normal oral glucose tolerance test were eligible for the trial. Between January 1989 and October 1995, 1736 relatives of patients with Type I diabetes were screened for ICA. We identified 64 cases $(3.7 \%)$ with ICA values more than 20 JDF-U. Of ICA positive relatives, 17 (27\%) had a low FPI and were eligible for enrolment. Of these 14 agreed to participate, of whom 7 were randomised to the treatment group and 7 to the control group. In the treatment group, human insulin was administered i.v. by continuous infusion for 7 days, followed by daily s.c. injections for 6 months. Intravenous insulin infusions were repeated every 12 months. In the treatment group 3 of the 7 individuals (follow-up from time of eligibility: 2.3 to 7.1 years) and in the control group 6 of the 7 untreated individuals (1.7 to 7.1 years) developed clinical diabetes. Life table analysis showed that clinical onset of Type I diabetes was delayed in insulin-treated subjects compared with control subjects (means \pm SEM diabetes-free survival: $5.0 \pm 0.9$ years vs $2.3 \pm 0.7$ years, $p<0.03$ ). Insulin levels after i.v. glucose increased in the first year of intervention therapy. Titres of ICA, and antibodies to glutamic acid decarboxylase, and tyrosine phosphatase-like protein IA2 remained unchanged. These data suggest that insulin prophylaxis can delay the onset of overt diabetes in high risk relatives. This is encouraging in view of 1 ) the continuing American Diabetes Prevention Trial, which is currently testing the effect of parenteral insulin in a large nation-wide study and 2) the initiation of pilot trials to determine whether new antigen-specific intervention is more effective in delaying the clinical onset of Type I diabetes. [Diabetologia (1998) 41: 536-541]

Keywords Type I (Insulin-dependent) diabetes mellitus, intervention, prevention, autoantibodies, insulin-prophylaxis.
Received: 2 September 1997 and in revised form: 20 December 1997

Corresponding author: Dr. A.-G. Ziegler, Hospital MünchenSchwabing, Diabetes Research Institute, Kölner Platz 1, 80804 Munich, Germany

Abbreviations: OGTT, Oral glucose tolerance test; IVGTT, intravenous glucose tolerance test; IAA, insulin autoantibodies; GADA, antibodies to glutamic acid decarboxylase; IA2A, antibodies to tyrosine phosphatase like protein IA-2; ICA, islet cell antibodies; FPI, first phase insulin response; DENIS, Deutsche Nikotin amid Interventions-Studie.
Type 1 diabetes is an autoimmune disorder in which the destruction of insulin-producing beta-cells can be detected years before the clinical manifestation of the disease [1]. Selective autoantibody assays and metabolic testing can now identify first degree relatives of Type I diabetic patients, in whom the risk of diabetes is over $80 \%$ at 5 years [2,3]. The ability to identify subjects at risk makes the exploration of immune intervention strategies to halt or even prevent betacell destruction a major goal. Growing evidence in animal models of Type I diabetes mellitus suggests 
that prophylactic insulin treatment can halt the autoimmune process and prevent the disease [4]. Possible mechanisms by which prophylactic insulin therapy may be effective involve both the concept of "betacell rest" and induction of active immunoregulation $[4,5]$.

In human pre-Type I diabetes, prophylactic insulin has been used for the first time at the Joslin Diabetes Center, USA [6]. In this uncontrolled study, five relatives at high risk of Type I diabetes received 5 days of i.v. insulin every 9 months, alternating with daily s.c. insulin treatment. After 3 years of follow up, one of the five developed diabetes, while all seven of those who declined treatment were diabetic [6].

In 1990, one year after the beginning of the Joslin trial, we initiated a randomised pilot study (Schwabing Insulin Prophylaxis Pilot Trial) to test the effect of i.v. and s.c. insulin in a high risk population in Germany. We used similar inclusion criteria but a simpler protocol in which i.v. insulin was given every 12 months but s.c. insulin was given for only 6 months. After up to 7 years of follow up we present results including life table analysis of the risk of diabetes progression, and metabolic and autoantibody data under antigen-specific intervention.

\section{Subjects and methods}

Inclusion criteria for eligibility into the trial were the following: first degree relatives of patients with Type I diabetes, aged 4 years or more, islet cell antibody (ICA) greater than 20 Juvenile Diabetes Foundation Units (JDF-U) in at least two consecutive serum samples, first phase insulin response (FPI, $1+3 \mathrm{~min}$ ) to an i.v. glucose tolerance test (IVGTT) less than 5 th centile $(<65 \mu \mathrm{U} / \mathrm{ml})$, and a normal oral glucose tolerance test (OGTT). Between January 1989 and October 1995, 1736 relatives of patients with Type I diabetes were screened for ICA at our institute. We identified 64 subjects $(3.7 \%)$ with ICA more than $20 \mathrm{JDF}-\mathrm{U}$ and in all of them ICA positivity was confirmed in a second serum sample. Of the ICA positive subjects 3 had an abnormal OGTT and were excluded from further investigation. There were 55 ICA-positive relatives who had an IVGTT test and 17of these had a low FPI to IVGTT and were therefore eligible for enrolment. There were 14 subjects who agreed to participate and they were, from June 1990 to October 1995, randomised one by one to treatment or no treatment (see numbers of randomisation and month of entry to trial in Table 1 ). There were 3 individuals who refused enrolment because they preferred to participate in DENIS (German Nicotinamide Intervention Trial). Before entry into the trial, all subjects in the treatment group including their family members underwent a training in self-monitoring of blood glucose levels by using a glucose meter, in the technique of insulin injection, and in recognising the symptoms of and treatment for hypoglycaemia. Blood glucose testing was scheduled four times daily, once before each meal and once at bedtime. Parents monitored the blood glucose levels in children aged 13 years or younger. Seven subjects were first treated with a course of i.v. insulin for 7 days, followed by one period of s.c. insulin for 6 months. Intravenous insulin for 7 days was repeated every 12 months. For the i.v. insulin treatment, subjects were admitted to hospital. Short-acting human insulin (H-insulin, Hoechst, Germany) was given by an insulin pump (H-Tron 100, Hoechst, Germany) connected to a small venous catheter placed into the subject's forearm. The initial insulin dosage was started at $0.1 \mathrm{U}$ per $\mathrm{h}$ to titrate the dosage, while blood glucose levels were checked hourly by blood glucose meters for the first six hours. The insulin dosage was then adjusted to maintain fasting and non-mealtime glucose levels between 3.3 and $3.9 \mathrm{mmol} \cdot \mathrm{l}^{-1}(60$ and $70 \mathrm{mg} / \mathrm{dl})$ and postprandial glucose levels below $5.0 \mathrm{mmol} \cdot \mathrm{l}^{-1}(90 \mathrm{mg} / \mathrm{dl})$. In adults, the s.c. insulin regimen incorporated three daily pre-meal injections of short-acting human insulin, and one injection of intermediate-acting insulin at bedtime. In children aged 13 years or less, two daily injections of a mixture of short-acting and intermediate-acting insulin were given. Patients were advised to reduce their s.c. dosage when preprandial blood sugar levels were below $3.3 \mathrm{mmol} \cdot \mathrm{l}^{-1}(60 \mathrm{mg} / \mathrm{dl})$ or in the case of hypoglycaemic reactions. OGTT, IVGTT, and autoantibody measurements were performed at trial entry, at 9 months, i.e. three months after s.c. treatment had stopped, at 12 months and then yearly prior to i.v. treatment. The study was approved by the local ethical board of the Bayerische Ärztekammer, Munich. Written consent for participation in the trial was obtained from all subjects, and, in the case of minors, from their parents.

Autoantibody assays and determination of insulin. Antibodies to insulin (IAA), glutamic acid decarboxylase (GADA), tyrosine phosphatase like protein IA-2 (IA2A), and islet cells (ICA) were analysed as described previously [7, 8]. The upper limit of normal values was defined by the 99th centile of antibody levels in a non-diabetic control population (IAA $50 \mathrm{nU} /$ ml; GADA 13 U; IA2A; 5 U, and ICA; 5 JDF-U) [8]. Antibody assays were entered into the Antibody Proficiency Program (organised by Dr. N. MacLaren, Gainesville, Fl., USA). Specificity and sensitivity respectively were $100 \%$ and $100 \%$ for the IAA assay, $100 \%$ and $94 \%$ for the GAD assay, $100 \%$ and $100 \%$ for the IA2A assay and $100 \%$ and $67 \%$ for the ICA assay. Plasma-insulin was measured by a RIA as described [9]. IVGTT were performed according to a standardised protocol [10].

Trial design. The trial was designed as a pilot study to provide preliminary data on a treatment protocol different from that used in the Joslin pilot study. With a sample size of 14 subjects, we were able to detect a $50 \%$ reduction in diabetes risk - from $80 \%$ in the control group to $30 \%$ in the insulin-treated group by assuming a power of $50 \%$ and an alpha $(p)$ of 0.05 . Life table analysis of the data was planned as soon as $80 \%$ of the control group developed clinical Type I diabetes.

Statistical analysis. Kaplan-Meier life table analysis was used to determine the cumulative risk of type I diabetes during follow up. Follow up started on the day of entry into the trial and ended with the onset of diabetes or, for this analysis, on 1 July 1997. "Minus" follow up years as shown in Figures 2, 3 , and 4 reflect years of follow up before patients fulfilled eligibility criteria for entry into the trial. Differences in diabetes-free survival between the groups were determined by log-rank test using the Statistical Package for Social Sciences (SPSS, Chicago, Il., USA). Confidence intervals $(95 \% \mathrm{Cl})$ for the cumulative risk were calculated from the standard error thereof. FPI ( 1 and $3 \mathrm{~min}$ ) and levels of autoantibodies at baseline and at different times during follow up were calculated by using Wilcoxon's matched-pairs signed ranks test for paired couples. Differences in baseline characteristics between the groups, such as age, FPI secretion, and $\mathrm{HbA}_{1 \mathrm{c}}$ were compared by Mann-Whitney U-Wilcoxon rank sum test. 
Table 1. SIP, baseline characteristics and follow up of trial subjects

\begin{tabular}{|c|c|c|c|c|c|c|c|c|c|c|c|c|c|c|c|}
\hline \multirow{2}{*}{$\begin{array}{l}\text { Rando- } \\
\text { misation } \\
\text { no. }\end{array}$} & \multirow{2}{*}{$\begin{array}{l}\text { Entry } \\
\text { (month/ } \\
\text { year) }\end{array}$} & \multirow{2}{*}{$\begin{array}{l}\text { Age, } \\
\text { (years)/ } \\
\text { sex }\end{array}$} & \multirow{2}{*}{$\begin{array}{l}\text { Relation } \\
\text { to patient } \\
\text { with } \\
\text { diabetes }\end{array}$} & \multicolumn{4}{|c|}{ Autoantibodies at baseline } & \multicolumn{2}{|c|}{ HLA } & \multicolumn{3}{|c|}{ Metabolic tests at baseline } & \multirow{2}{*}{$\begin{array}{l}\begin{array}{l}\text { Treat- } \\
\text { ment }\end{array} \\
\text { Insulin } \\
(\mathrm{U} / \mathrm{kg} / \\
\text { day) }\end{array}$} & \multicolumn{2}{|c|}{$\begin{array}{l}\text { Follow up } \\
\text { (years) }\end{array}$} \\
\hline & & & & $\begin{array}{l}\text { ICA } \\
(\mathrm{JDF}-\mathrm{U})\end{array}$ & $\begin{array}{l}\text { IAA } \\
(\mathrm{nU} / \mathrm{ml})\end{array}$ & $\begin{array}{l}\text { GADA } \\
(\mathrm{U})\end{array}$ & $\begin{array}{l}\text { IA2A } \\
(\mathrm{U})\end{array}$ & DR & DQB1 & $\begin{array}{l}\text { FPI } \\
1+3 \text { min } \\
(\mathrm{mU} / \mathrm{l})\end{array}$ & $\begin{array}{l}\text { OGTT } \\
\mathrm{fbg} / 120 \\
(\mathrm{mg} / \mathrm{dl})\end{array}$ & $\begin{array}{l}\mathrm{HbA}_{1 \mathrm{c}} \\
(\%)\end{array}$ & & $\begin{array}{l}\text { no } \\
\text { Type I }\end{array}$ & $\begin{array}{l}\text { to } \\
\text { Type I }\end{array}$ \\
\hline \multicolumn{16}{|c|}{ Insulin-treated group } \\
\hline 1 & $6 / 90$ & $46 / \mathrm{m}$ & Daughter & 80 & 5 & 123 & 2 & $4 / 4$ & $0302 / 0302$ & 27 & $3 \cdot 9-6 \cdot 3$ & 5.0 & 0.32 & 7.11 & \\
\hline 3 & $10 / 90$ & $17 / f$ & Father & 320 & 71 & 71 & 99 & $4 / 4$ & $0302 / 0302$ & 47 & $4 \cdot 5-7 \cdot 2$ & 5.1 & 0.21 & & 4.3 \\
\hline 5 & $2 / 92$ & $13 / \mathrm{m}$ & Sister & 320 & 453 & 53 & 13 & $3 / 4$ & 0201/0302 & 57 & $5 \cdot 2-6 \cdot 9$ & 5.9 & 0.40 & & 4.15 \\
\hline 7 & $3 / 93$ & $4 / \mathrm{m}$ & Father & 160 & 106 & 106 & -3 & $3 / 11$ & 0201/0301 & 36 & $4 \cdot 2-5 \cdot 9$ & 5.6 & 0.17 & 4.37 & \\
\hline 9 & $4 / 93$ & $6 / f$ & Sister & 80 & 899 & 15 & 20 & $1 / 4$ & 0501/0201 & 42 & $2 \cdot 9-4 \cdot 7$ & 5.4 & 0.68 & 4.28 & \\
\hline 11 & $2 / 94$ & $4 / \mathrm{m}$ & Father & 160 & 2811 & 17 & 92 & $4 / 6$ & $0302 / 0603$ & 48 & $4 \cdot 2-5 \cdot 3$ & 5.2 & 0.31 & & 0.58 \\
\hline 13 & $3 / 95$ & $19 / \mathrm{f}$ & Sister-twin & 40 & 72 & 49 & -5 & $4 / 4$ & $0302 / 0302$ & 44 & $4 \cdot 2-5 \cdot 8$ & 4.8 & 0.20 & 2.35 & \\
\hline \multicolumn{16}{|c|}{ Control group } \\
\hline 2 & $6 / 90$ & $8 / f$ & Father & 160 & 1100 & 83 & 94 & $3 / 8$ & 0201/0402 & 43 & $5 \cdot 3-6 \cdot 0$ & 5.0 & - & & 4.19 \\
\hline 4 & $7 / 91$ & $13 / \mathrm{f}$ & Sister/Father & 80 & 24 & 108 & 82 & $3 / 4$ & 0201/0302 & 40 & $4 \cdot 9-6 \cdot 5$ & 5.6 & - & & 0.43 \\
\hline 6 & $3 / 92$ & $24 / \mathrm{f}$ & Father & 320 & 20 & 30 & 74 & $3 / 13$ & 0201/0604 & 40 & $4 \cdot 2-6 \cdot 2$ & 4.7 & - & & 0.67 \\
\hline 8 & $4 / 93$ & $4 / f$ & Father & 160 & 1465 & 139 & 11 & $2 / 4$ & $0502 / 0302$ & 51 & $4 \cdot 7-5 \cdot 7$ & 5.6 & - & & 3.75 \\
\hline 10 & $7 / 93$ & $55 / \mathrm{f}$ & Son & 40 & 176 & 51 & 0 & $4 / 6$ & $0302 / 0603$ & 40 & $5 \cdot 5-6 \cdot 8$ & 5.0 & - & 4.09 & \\
\hline 12 & $3 / 94$ & $13 / \mathrm{f}$ & Father & 160 & 189 & 81 & 107 & $4 / 6$ & $0302 / 0604$ & 58 & $4 \cdot 8-6 \cdot 8$ & 5.3 & - & & 2.57 \\
\hline 14 & $10 / 95$ & $17 / \mathrm{m}$ & Brother & 80 & 40 & 3 & 59 & n.d. & n.d. & 16 & $4 \cdot 4-5 \cdot 2$ & 5.2 & - & & 0.42 \\
\hline
\end{tabular}

FPI: first phase insulin secretion, OGTT: oral glucose tolerance test, fbg: fasting blood glucose, n. d.: not determined, antibody levels above upper limit of normal values are printed in bold: ICA: 5 JDF-U, IAA: $50 \mathrm{nU} / \mathrm{ml}$, GADA: 13 U, IA2A: 5 U

\section{Results}

Patient characteristics at baseline. Subjects in the treatment and control groups did not differ in respect of baseline data such as age (treatment group, mean 15.6 years, range 4 to 46 years; control group mean, 19.1 years, range 4 to 55 years, $p=0.8$ ), $\mathrm{HbA}_{1 \mathrm{c}}$ (treatment group, means $\pm \mathrm{SD} 5.3 \% \pm 0.4$; control group, $5.2 \% \pm 0.4, p=0.7)$, and FPI secretion $(1+3 \mathrm{~min})$ (treated, means \pm SD: $43 \pm 9.5 \mu \mathrm{U} / \mathrm{ml}$; control group, $41.2 \pm 13.0 \mu \mathrm{U} / \mathrm{ml}, p=0.7$ ) (Table 1 ). In addition, the antibody status at entry into the trial did not differ between the two groups. In the insulin-treated group, besides ICA, one subject had one, two individuals had two, and four subjects had three antibodies. Similarly, in the non-treated group one subject had one, three individuals had two, and three subjects had three additional antibodies besides ICA (Table 1). Only in one subject (no 1, Table 1), was ICA staining completely inhibited by competition with GAD65 (gift from E. Bonifacio, Milan, Italy), indicating that this person had "GAD"ICA antibodies. Six insulin-treated subjects and four control subjects had IAA, and similarly, four insulin-treated and six control subjects had IA2A. The mean daily insulin dose of treated patients ranged from 0.17 to $0.68 \mathrm{U} / \mathrm{kg}$ body weight (Table 1 ). All subjects tolerated the treatment very well. Two individuals reported episodes of mild hypoglycaemia, which could be relieved by drinking orange juice or sweet tea. Severe hypoglycaemia or symptoms of altered consciousness were not observed.

Diabetes outcome. During follow up, three of the seven subjects treated with insulin and six of seven in the control group developed Type I diabetes. Follow up from the time of eligibility for the trial until 1 July, 1997 or until the onset of diabetes, ranged from 0.6 to 7.1 years in the treated group and from 0.4 to 4.2 years in the control group. Life table analysis showed that the mean diabetes-free survival time in the insulintreated group was significantly increased compared with the control group (mean [ $95 \% \mathrm{Cl}] 5.0$ years, [3.2 to 6.8] years, vs. 2.3 years, [1.0-3.6] years, $p<0.03$, log-rank test) (Fig.1). After one and four years, respectively, risk of type 1 diabetes was lower in the insulin-treated group (mean $[95 \% \mathrm{Cl}] 14 \%,[0$ to $40 \%]$ ) than in the control group (43\% [6 to $80 \%$ ] at 1 year, $71 \%$ [38 to $100 \%$ ] at 4 years).

Effect on metabolic parameters. Within the first year of insulin prophylaxis, FPI secretion improved in

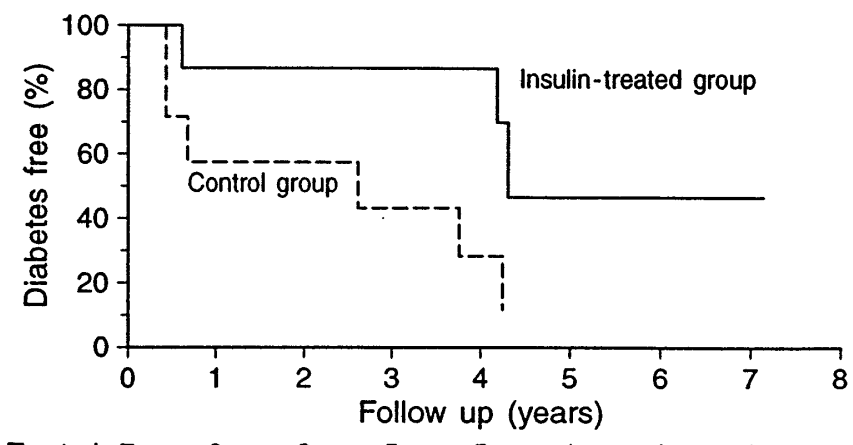

$\begin{array}{lllllllll}\text { Treated } & 7 & 6 & 6 & 5 & 5 & 1 & 1 & 1 \\ \text { Control } & 7 & 4 & 4 & 4 & 1 & & & \end{array}$

Fig. 1. Kaplan-Meier survival analysis for the cumulative risk of Type I diabetes in trial subjects - high risk, first degree relatives. The mean diabetes-free survival time in the insulin treatment group was significantly longer than that in the control group (5.0 years versus 2.3 years, $p=0.028$ ) 

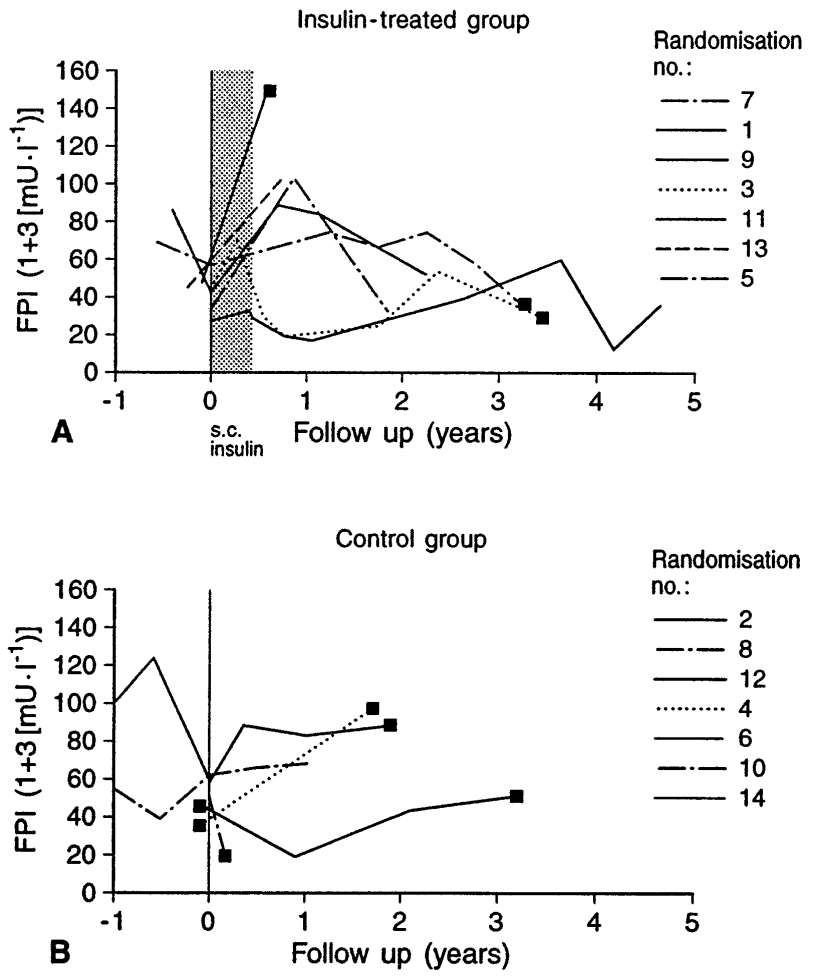

Fig. 2. FPI secretion $(1+3 \mathrm{~min})$ at baseline and during follow up in the insulin treated group $(p=0.018)(\mathbf{A})$ and control group $(p=0.6)(\mathbf{B})$. The grey column represents the period of s.c. insulin therapy. Vertical lines represent the time of recruitment into the trial. "Minus" follow up years reflect years of follow up before patients fulfilled eligibility criteria for entry into the trial. (ם) Individuals who developed diabetes during follow up

most subjects (median at 1 year: $89 \mu \mathrm{U} / \mathrm{ml}$, mean \pm SD: $83 \pm 43 \mu \mathrm{U} / \mathrm{ml}$ compared with baseline: median $44 \mu \mathrm{U} / \mathrm{ml}$, mean \pm SD: $43 \pm 10 \mu \mathrm{U} / \mathrm{ml}, p=0.018)$, but the improvement was not lasting (Fig. 2). For reasons inherent to the collection process of the blood samples, antibodies bound from free insulin were not separated prior to the determination of insulin by radioimmunoassay. Therefore, it can not be ruled out that insulin levels were partly influenced by increased insulin antibody levels.

Effect on humoral islet autoimmunity. Antibodies to insulin increased dramatically during the first six months of parenteral insulin administration in five of seven relatives (Fig.3). ICA persisted in all patients with titres above 20 JDF-U. Similarly, although GADA and IA2A titres showed some major fluctuation, they generally remained unchanged during prophylactic insulin treatment (Fig.4). One patient in the insulin-treated (no 7) and one patient in the control group (no 10) developed IA2A.
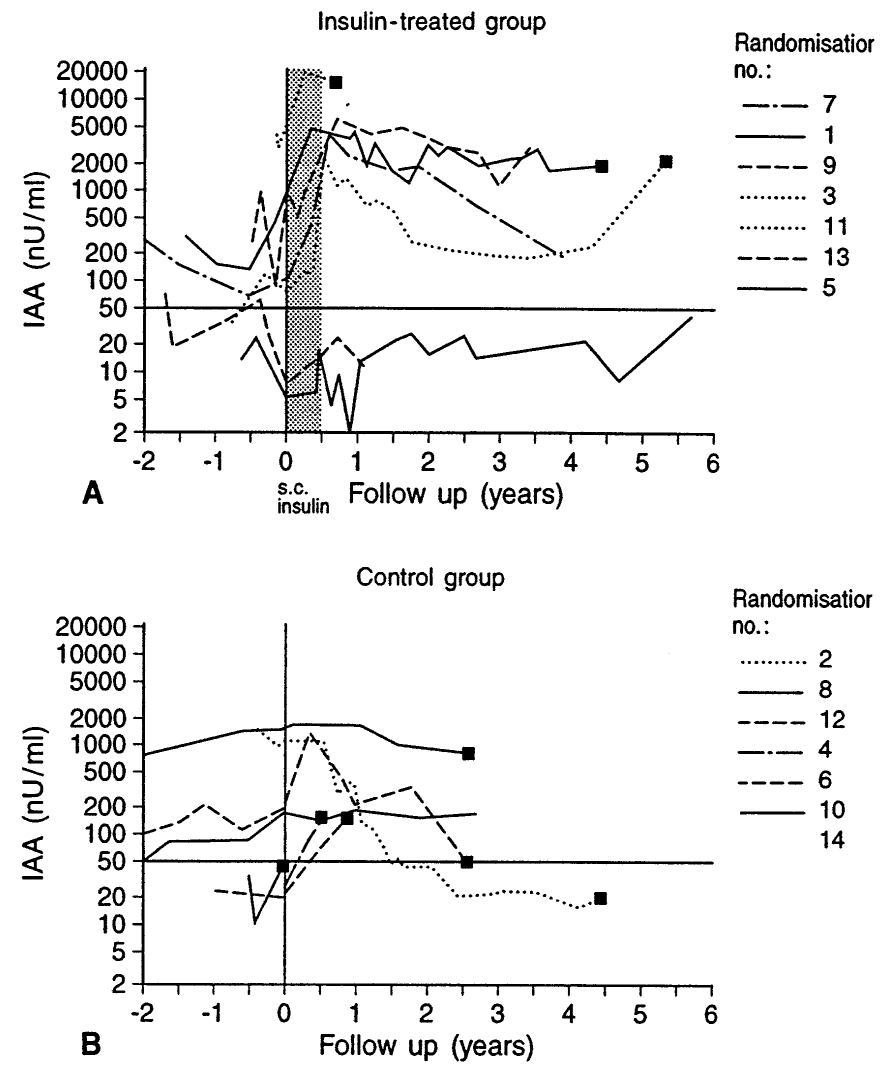

Fig. 3. Levels of circulating insulin (auto)-antibodies I[A]A in insulin-treated group $(p=0.009)(\mathbf{A})$ and control group $(\mathbf{B})$ before and after the start of the trial. Values are on a logarithmic scale. The grey column represents the period of s.c. insulin therapy. Horizontal lines indicate the upper limit of antibody values. "Minus" follow up years reflect years of follow up before patients fulfilled eligibility criteria for entry into the trial. (ם) Individuals who developed diabetes during follow up

\section{Discussion}

Our randomised pilot trial tested the protective effect of prophylactic parenteral insulin therapy in relatives at high risk for Type I diabetes. Life table analysis showed that treatment afforded protection from Type I diabetes. This study confirms results previously reported by Keller et al., that insulin prophylaxis delays the clinical onset of Type I diabetes [5]. This is encouraging although, for both pilot studies, it is important to note that the number of individuals included was small and the results must therefore be interpreted with caution. Questions on the extent to which individuals at high risk will profit from insulin based therapies will definitely be answered by the continuing Diabetes Prevention Trial (DPT-1 trial) which is currently testing the effect of parenteral and oral insulin in a large nationwide multicentre study [11].

We used ICA positivity and FPI secretion impairment as inclusion criteria for our trial because at the time of study design other antibody markers were ei- 
A
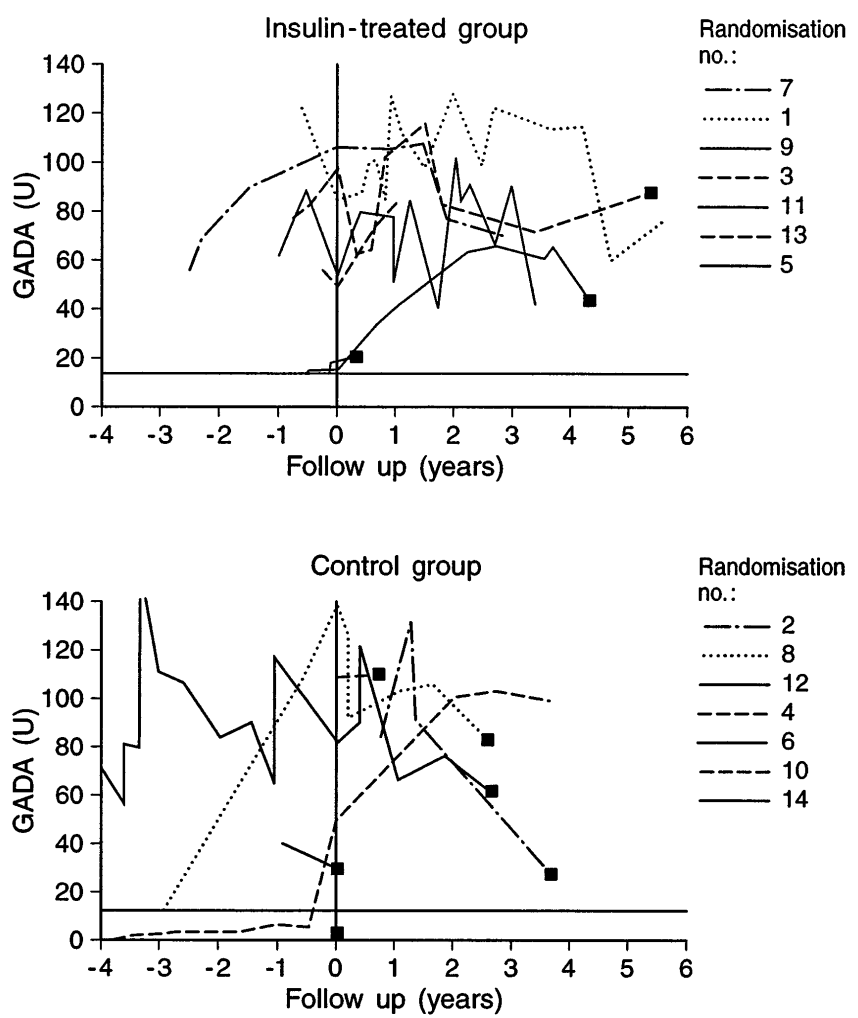

Fig. 4. GADA (A) and IA2A (B) values during follow up in the insulin treated group (upper panel) and control group (lower panel). Horizontal lines denote the upper limit of antibody values, vertical lines represent the time of recruitment into the trial. "Minus" follow up years reflect years of follow up before patients fulfilled eligibility criteria for entry into the trial. ( $\square$ ) Individuals who developed diabetes during follow up

ther not available or had not been evaluated in respect of risk of diabetes progression. Today we know, that the risk of progression to clinical diabetes depends not only on the ICA-titre and the FPI level but is also associated with the number of positive antibodies [3]. We tested thus all available antibody markers such as IAA, GADA, and IA2A in our study population. Most importantly, autoantibody status in terms of the number of additional antibodies in addition to ICA at baseline were very similar when insulin-treated and control groups were compared, suggesting that the randomisation of subjects to each group was satisfactory in that respect. In fact, most subjects were high risk in that they had more than one defined antibody specificity. Furthermore, no differences between treated and control subjects were found with regard to age, $\mathrm{FPI}$, and $\mathrm{HbA}_{1 \mathrm{c}}$ at baseline. Finally, HLA typing showed no difference in the distribution of risk-associated DR/DQ-alleles between the two groups. These findings suggest that the delay in diabetes onset seen in our study is the result of prophylactic insulin treatment, not unequal distribution
B
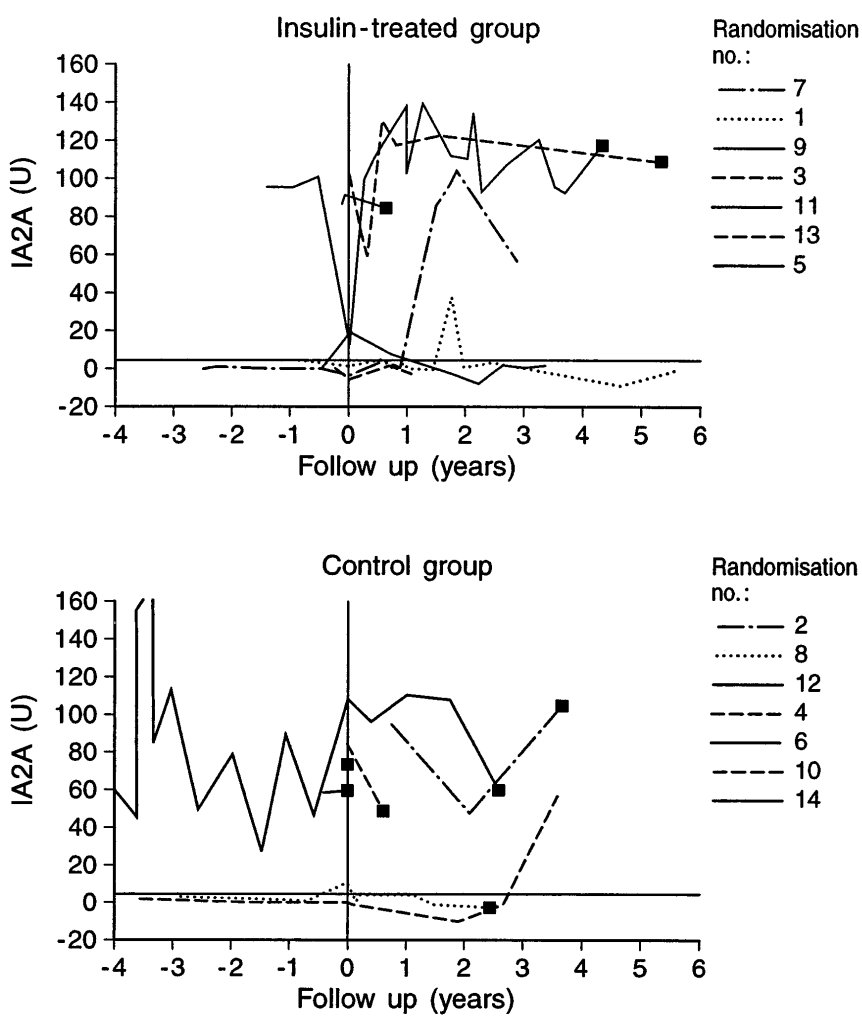

in the risk of Type I diabetes between treated and control subjects.

However, protection from impending Type I diabetes was not complete as suggested by our life table analysis. This implies that antigen specific therapy when applied at a late stage in the disease process, that is, at a stage where many beta cells are severely damaged, does not lead to a permanent suppression of autoimmunity.

Our treatment regimen of temporary or intermittent insulin may give additional reasons for the lack of permanent protection. After the first six months of daily s.c. insulin injection, FPI secretion (as an indicator of beta-cell function) and insulin antibody production (as an indicator of immune activation) increased. After withdrawal of s. c. treatment, but while i. v. treatment was taking place, both levels of insulin secretion and insulin antibody titres dropped. This may suggest that continuous administration of s.c. insulin, or at least repeated blocks of s.c. application may be more efficient in preserving beta-cell function and preventing clinical disease. The fact that all antibody markers remained positive under immune intervention also supports the assumption that autoimmunity towards beta cells continues. Similar findings have been reported under immunosuppression with cyclosporin after the onset of overt Type I diabetes [12].

In summary these data show that parenteral administration of insulin - even when given only on a temporary basis - can delay the manifestation of clin- 
ical diabetes by 2 to 3 years. We believe that our noncontinuous treatment protocol in this study has a clear advantage over the protocols used by the Joslin-trial and by the Diabetes Prevention Trial $[5,11]$. It should therefore be considered to test such temporary treatment concepts in larger studies. Clear disadvantages of protocols for all three studies $[5,11]$ are the admission to hospital for treatment and the cumbersome IVGTT which is difficult to perform for paediatricians in private practice. We therefore suggest that for future intervention trials, risk evaluation and staging should be based only on the numbers of elevated antibodies. Also, treatment protocols should be considered that are more convenient and practical for high risk individuals including subjects in the general population. One such new therapeutic concept that has been shown to be successful in animal models of autoimmune diabetes may be insulin-vaccination [13].

Acknowledgements. This study was supported by grants from the Wilhelm Sander Stiftung (89.029.2) and the Hoechst, AG, Germany (Dr. D.Leihener). The authors are grateful to Dr. R. Schwertner, Dr. M.Hummel, and M.Schenker for support in clinical care of the patients. We thank U.Mollenhauer, J. Vordemann, and M.Dübell for expert technical assistance, and Dr. A. Markuzzi for statistical advice.

\section{References}

1. Eisenbarth GS, Ziegler AG (1995) Type 1 diabetes mellitus. In: Weintraub BD (ed) Molecular endocrinology: basic concepts and clinical correlations. Raven Press, New York, pp 269-282

2. Bingley PJ, Christie MR, Bonifacio E et al. (1994) Combined analysis of autoantibodies improves prediction of
IDDM in islet cell antibody-positive relatives. Diabetes 43: $1304-1310$

3. Verge CF, Gianani R, Kawasaki E et al. (1996) Prediction of type I diabetes in first degree relatives using a combination of insulin, GAD, and ICA512bdc/IA-2 autoantibodies. Diabetes 45: 926-933

4. Füchtenbusch M, Ziegler AG (1996) Prophylactic insulin treatment in pre-type-1-diabetes In: Marshall SM, Home PD, Rizza RA (eds) The diabetes Annual (no 10), Elsevier Science BV, Amsterdam pp 135-146

5. Schloot N, Eisenbarth GS (1995) Isohormonal therapy of endocrine autoimmunity. Immunology Today 16: 289-294

6. Keller RJ, Eisenbarth GS, Jackson RA (1993) Insulin prophylaxis in individuals at high risk of type 1 diabetes. Lancet 341: 927-928

7. Christie MR, Roll U, Payton MA, Hatfield ECI, Ziegler AG (1997) Validity of screening for individuals at risk for type 1 diabetes by combined analysis of antibodies to recombinant proteins. Diabetes Care 20: 965-970

8. Roll U, Christie MR, Füchtenbusch M, Payton MA, Hawkes CJ, Ziegler AG (1996) Perinatal autoimmunity in offspring of diabetic parents. The German multicenter BAB Y-DIAB study: detection of humoral Immune responses to islet antigens in early childhood. Diabetes 45: 967-973

9. Soeldner JS, Slone D (1965) Critical variables in the radioimmunoassay of serum insulin using the double antibody technic. Diabetes 14: 771-779

10. Position statement: prevention of type I diabetes mellitus (1990) Diabetes Care 13: 1026

11. The DPT-1 Study Group. The diabetes prevention trialtype 1 diabetes (DPT-1). Enrollment report (1997) Diabetes 46: Suppl. 1 A0630

12. Martin S, Schernthaner G, Neryp J et al. (1991) Follow-up of cyclosporin A treatment in type 1 (insulin-dependent) diabetes mellitus: lack of long term effects. Diabetologia 34: 429-434

13. Muir A, Peck A, Clare-Salzler MC et al. (1995) Insulin immunization of nonobese diabetic mice induces a protective insulitis characterized by diminished intraislet interferon- $\gamma$ transcription. J Clin Invest 95: 628-634 